\section{Pensamento em construção: Excurso sobre as possíveis maquinações metodológicas de Sérgio Ferro para orientar Estudos de Produção em Arquitetura, Projeto e Trabalho}

Thought under construction: Excursus on the possible methodological machinations of Sérgio Ferro to guide Production Studies in Architecture, Design and Labour

João Marcos de Almeida Lopes*

*Professor Titular no Instituto de Arquitetura e Urbanismo da Universidade de São Paulo (São Carlos). Coordena o Grupo de Pesquisa em Habitação e Sustentabilidade. Doutor em Filosofia e Metodologia das Ciências pela Universidade Federal de São Carlos, joaomarcosdealmeidalopes@gmail.com

\section{Palavras-chave:}

Sérgio Ferro:

Estudos de Produção.

\section{Keywords:}

Sérgio Ferro;

Construction Site and Design;

Production Studies
Canteiro e Desenho;

\begin{abstract}
Resumo
A obra escrita do professor, arquiteto e pintor brasileiro Sérgio Ferro tem sido cada vez mais visitada, estudada e comentada, não só no Brasil e na França - país em que se exilou, ao deixar o Brasil no início dos anos 1970, em virtude da ditadura civil-militar que se abateu sobre o país naquele período - como também em outras partes do mundo. A atenção dedicada à obra teórica de Ferro parece decorrer da forma particularmente instruída pela Economia Política, pela Lógica hegeliana e pelo materialismo dialético marxiano. Tomando como ponto de partida as bases materiais de sua produção, tanto da arquitetura como das artes plásticas, seus campos de investigação e reflexão histórica e teórica avançam por campos até então insondados, recolocando em julgamento concepções já consagradas e largamente consolidadas. Este do autor, buscando estabelecer referências para a instituição de um novo campo de estudos em Arquitetura, Projeto e Trabalho, que estamos denominando Production Studies.
\end{abstract}

usjt

\section{arq.urb}

número 29 | set-dez de 2020 Recebido: $17 / 06 / 2020$ Aceito: $30 / 09 / 2020$

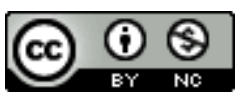

\section{Abstract}

The written work of Brazilian professor, architect, and painter Sérgio Ferro has been increasingly visited, studied, and commented on, not only in Brazil and France - the country in which he went into exile, when he left Brazil in the early 1970s, due to the civil-military dictatorship that befell the country in that period - as well as in other parts of the world. The attention devoted to Ferro's theoretical work seems to derive from the way he approaches his objects and gives them a critical and theoretical treatment, particularly instructed by Political Economy, Hegelian Logic, and Marxian dialectical materialism. Taking as a starting point the material bases of his production, both in architecture and in the plastic arts, his fields of historical and research and theoretical reflection advance through fields previously hitherto unexplored, putting wellestablished and widely consolidated concepts on trial. This work tests some conjectures about the author's methodological strategies, seeking to establish references for the institution of a new field of studies in Architecture, Design, and Work, which we are calling Production Studies. 
Pensamento em construção: Excurso sobre as possíveis maquinações metodológicas de Sérgio Ferro para orientar Estudos de Produção em Arquitetura, Projeto e Trabalho

Em novembro de 2014, em um evento acadêmico na Universidade de Newcastle (UK) - a Conferência Industries of Architecture - IOA -, uma plateia de mais ou menos 50 pessoas aplaudia crepitosamente a leitura de "Dessin/Chantier - an Introduction" - uma versão bastante condensada das principais ideias de "O Canteiro e o Desenho", texto do arquiteto, professor e pintor Sérgio Ferro, publicado no Brasil entre 1974 e $1976{ }^{2}$. Sérgio era o convidado para a conferência de abertura, mas devido a um problema de saúde, não conseguiu estar presente no encontro. Assim, Katie Lloyd Thomas, uma das organizadoras do evento, fez a leitura do texto enquanto as imagens do original em português eram projetadas, encerradas por uma conhecida foto do autor. Registro aqui, não só como depoimento, mas como a impressão de que germinava ali uma atenção inédita para as reflexões teóricas, em solo britânico, de um teórico da arquitetura brasileiro que nem sempre foi devidamente reconhecido ou compreendido em sua terra natal.

No começo de outubro de 2020, como resultado daquele evento de 2014 e de inúmeras articulações acadêmicas transnacionais, demos início a uma empreitada que vem sendo planejada há pelo menos seis anos: trata-se de promover a tradução e difusão da obra teórica de Sérgio Ferro em língua inglesa. Autor de uma abordagem crítica da arquitetura bastante singular, provocativa e muito rigorosa, razoavelmente conhecido em nosso meio (mas pouco compreendido, como já afirmamos), a obra de Sérgio Ferro está, em sua maior parte, publicada apenas em português. Alguma coisa em português e francês e uma pequena parte exclusivamente em francês. No entanto, fora algumas iniciativas recentes, já resultantes do esforço de montagem do projeto "Translating Ferro / Transforming Knowledges of Architecture, Design and Labour for the New Field of Production Studies

'Publicado em LLOYD THOMAS, K.; AMHOF, T.; BEECH, N. Industries of Architecture. London: Routledge, 2015.

${ }^{2}$ A edição completa, publicada pela Projeto Editores Associados, é de 1979. Antes dela, o texto já havia sido publicado em duas partes, na revista de filosofia Almanaque: Cadernos de Literatura e Ensaio (publicada pela Editora Brasiliense e que contava com o professor Bento Prado Jr como integrante de seu Conselho Editorial), sob o título "A forma da arquitetura e o desenho da mercadoria", em 1976. Ver nota de apresentação d' "O Canteiro e o desenho" em Arquitetura e Trabalho Livre (FERRO, 2006 p.105).
[TF/TK]" (conforme apresentado, nesta publicação, pela minha colega Katie Lloyd Thomas - a mesma que leu o "Dessin/Chantier - an Introduction" na abertura do IOA, em 2014), são praticamente inexistentes versões de textos seus em inglês.

A proposta, contudo, não se restringe exclusivamente à tradução e publicação de textos de Ferro e à promoção de alguns encontros de leitura e discussão com colegas acadêmicos falantes do inglês. A ideia é também identificar, selecionar e articular estudos, textos ou relatos de práticas que, de certa forma, dialoguem com os pressupostos que orientaram (e orientam) as formulações de Sérgio Ferro (e do Grupo Arquitetura Nova, do qual foi um dos integrantes, como ele mesmo insiste compartilhar $^{3}$ ). Além disso, o TF/TK também propõe a produção de estudos e relatos de práticas específicos, num primeiro momento distribuídos entre pesquisadores associados (Associated Researchers), orientados por abordagens alinhadas com a obra de Sérgio. É o que estamos chamando de Production Studies + Production Practices. A ideia é delinearmos um novo campo de estudos (e para reconhecimento de práticas) que se alimentem das estratégias metodológicas de Ferro.

Mas, o que seriam Production Studies? O que tem de peculiar na forma como Sérgio Ferro toma seus objetos e como constrói o pensamento sobre eles? Qual a diferencial metodológico que caracteriza esse verdadeiro 'canteiro de reflexão' em Arquitetura proposto por Sérgio perante os conceitos e seus desconcertantes movimentos?

O que ensaio aqui é uma aproximação ainda muito imprecisa de alguma resposta para estas questões, disposta ao debate e ao contraditório, fruto de um diálogo com o autor mais ou menos interessado em estabelecer algumas possíveis alternativas para essa indagação. Mais que isso, essas conjeturas pretendem auxiliar na elaboração de algumas diretrizes para ajustarmos o foco nessa formulação ainda muito difusa - os Production Studies.

${ }^{3} \mathrm{~A}$ respeito do grupo, seus integrantes - além de Sérgio Ferro, também Rodrigo Lefèvre e Flávio Império - e sobre as dobras e desdobramentos de sua atuação, ver, entre outros trabalhos, o de Ana Paula Koury, "Grupo Arquitetura Nova: Flávio Império, Rodrigo Lefèvre, Sérgio Ferro", publicado em 2003; e o de Pedro Fiori Arantes, "Arquitetura Nova: Sérgio Ferro, Flávio Império e Rodrigo Lefèvre, de Artigas aos mutirões", de 2002. 
Além disso, o canteiro de obras é uma estrutura produtiva especial, diferente da

Desde seus tempos de docência na Faculdade de Arquitetura e Urbanismo da Universidade de São Paulo (FAUUSP) e iniciando sua atividade profissional (algo ainda conciliável naqueles tempos), Sérgio Ferro vem sistematicamente produzindo uma obra teórica, reflexiva (quase obsessiva - ele mesmo se diz dominado por um "mantra"), muito dela referente às relações entre o canteiro e o desenho, às lógicas de produção do "objeto arquitetônico" como mercadoria, à história da arquitetura e da arte como manifestações culturais atinentes às dinâmicas de produção das mercadorias, às potencialidades do trabalho livre etc. Toma como pressuposto, para sua abordagem da história da arquitetura, que não só é possível como necessário entende-la por dentro da construção e fazer atravessar sua história pelas lentes da economia política ${ }^{4}$ para que consigamos compreender como ela promove e opera mecanismos de sobredeterminação estabelecidos pelo modo de produção e reprodução da vida. Só assim, segundo Ferro, é possível compreender como a arquitetura, como instância produtiva mergulhada no mundo da reprodução material (e não numa 'realidade' etérea de formulação puramente teórica e portadora de uma pretensa 'racionalidade própria'), cumpre papel fundamental nas mecânicas de reprodução de valor e de acumulação, através da sua capacidade radical de exploração do trabalho e extração de enormes massas de mais-valor, tanto absoluto como relativo.

O argumento é conhecido: pelo fato da construção tratar-se de uma manufatura especial, que envolve uma expressiva e extensa aplicação de mão-de-obra intensiva, ela permite a captura de altas taxas de mais-valor, transferidos liminarmente para outros segmentos econômicos, principalmente aqueles desprovidos de possibilidades de agenciamento intensivo de trabalho - este, a única atividade capaz de produzir valor ${ }^{5}$.

4"Acreditamos que é a partir da análise da construção, toda ela, dentro da economia política e, em seguida, da arquitetura dentro da construção, que poderemos compreender corretamente esta nossa atividade: desenhar, projetar" (FERRO, 2010 p.13).

${ }^{5} \mathrm{Para}$ compreender este processo - que para mim sempre foi muito nebuloso até então - sugiro a leitura da tese de doutoramento de Lucia Zanin Shimbo, "Habitação social, habitação de mercado. a confluência entre Estado, empresas construtoras e capital financeiro", de 2010. Nela a autora nos revela como os processos de financeirização e o jogo no mercado de capitais se sustentam nos mecanismos de controle e realização da produção no canteiro de obras habitacionais naquele período, transferindo as tais massas de mais-valor para as esferas de especulação e reprodução fábrica por uma condição inerente às suas particularidades: como já apontou Benjamin Coriat, na construção civil é a linha de produção que se move para gerar o produto que nasce imóvel - o contrário da fábrica, onde é o produto que caminha na linha de produção ${ }^{6}$. Isso deriva numa série de implicações - que aqui não é o caso de aprofundarmos: a sobredeterminação da propriedade fundiária no processo de produção na construção civil, os limites da industrialização estrito senso neste setor econômico ${ }^{7}$, a suscetibilidade às dinâmicas e oscilações do mercado de trabalho para agenciamento e aplicação de mão-de-obra etc. Mas ao observarmos o canteiro de obras como o principal momento produtivo de toda e qualquer arquitetura, parece-nos claro o quão externamente determinado é seu desenvolvimento no curso da História e o quanto se esvanece como realidade produtiva quando se impõe a obra acabada - e parece ser este, justamente, o recurso de Ferro para compreender os movimentos do desenho e do canteiro de obras: a História como processo em processo. Esta é minha primeira conjetura quanto às suas possíveis maquinações metodológicas.

A história factual nos oferece, sem dúvida, a possibilidade de referirmos os eventos no tempo e no espaço, permitindo análises mais aprofundadas, para além do chão de suas manifestações aparentes. Contudo, o que articula tais eventos? Seria possível referenciar alguma racionalidade inerente e interna aos fatos se o material de suas manifestações se encontra no submundo do reino das aparências - o que torna essa racionalidade irritantemente transparente?

de capital na forma de fabulosas negociações no mercado de capitais e carteiras imobiliárias tudo isso sob as graças de um programa público de provisão habitacional, o "Minha Casa, Minha tudo isso sob as graças
Vida" (SHIMBO, 2010).

6"Bernard Kündig pode dizer que, pelo fato de sermos obrigados a recorrer à terra como suporte de valor de uso, é o próprio processo de trabalho, e em todo seu conjunto, que "circula" e deve cada vez se adaptar a um suporte diferente, ao contrário das outras indústrias onde é o produto que circula entre os postos de um trabalho estável e previsto anteriormente" (CORIAT, 1983 p.3).

${ }^{7}$ Isto é, fabricação industrializada de seus produtos, considerando mecanização e/ou automatização intensiva de operações e processos. A Dymaxion House de 1946, de Richard Buckminster Fuller, por exemplo, demandaria uma outra estrutura de propriedade fundiária para se viabilizar uma proposta de construção altamente industrializada, leve e transportável, mas que exigiria um arcabouço de distribuição da localização bastante diverso do vigente (ver https://blogs.uoregon.edu/dymaxionhouse/a-house-is-a-machine-for-living-in/). 
ando-lhe os elementos para sua crítica radical (HARVEY, 2013 p.15). Penso que

Em primeiro lugar, a pesquisa de Sérgio não se resume à História da Arquitetura, estrito senso. Além de assentar os fundamentos do pensamento especulativo na dialética hegeliana, bem como no materialismo histórico e na crítica da Economia Política construída por Marx, Sérgio também convoca a história da arte, da técnica e da construção para conjugar as dimensões materiais da produção do objeto arquitetônico à sua indagação como produto de Cultura. Não só, o autor articula também abordagens estratégicas da lógica formal em Filosofia (como o exercício de abdução, a partir da semiótica de Peirce, por exemplo, para dar conta da análise da Capela dos Médici, em Florença - ver FERRO, 2016²), da Antropologia Estrutural (como a referência à "forma tipo zero" de Lévi Strauss, para enunciar "a razão prioritária do desenho" no momento da produção - ver FERRO, 2006 p.109), da Sociologia e da Ciência Política (para analisar a produção da casa no Brasil - idem, p.61-101) etc. Mas é no material da História, propriamente dita, onde ele vasculha com afinco as referências para suas reflexões. Ele mesmo, certa feita, comentando a elaboração de "Concrete as Weapon" (FERRO, 2018), disse ter enfrentado a leitura de "um catatau de 600 páginas de história do anarquismo na França" para dele usar um único parágrafo.

Numa primeira visada, parece certo que Sérgio Ferro alcançou uma forma original de conciliar as narrativas da historiografia da Arquitetura com as abordagens mais críticas da Economia Política. Como diz Harvey sobre Marx enfrentando a tradição clássica da Economia Política, ao procurar suas "lacunas e contradições" foi-lhe possível "o que hoje chamamos de desconstrução" de seus argumentos, propici-

${ }^{8}$ Nessa obra, vertida do francês em 2015 e publicada em 2016, Sérgio promove uma reconstrução de todo o contexto em torno do projeto e construção da Capela dos Médici, na Basílica de San Lorenzo, em Florença, empreendido por Michelangelo e seus 'operários'. A partir desse esforço de reconstituição de um tempo e de um espaço muito peculiar - fazendo uso da observação, da história geral e da arte, de elementos da escultórica, da ciência dos materiais, da literatura etc. Sérgio se permite recompor as ordens da encomenda e a resposta dada por Michelangelo: trabalho portrangido do arquiteto, registrado nos anda: ãa ç perme rir finalizacão. A re seus contratantes, ironizar suas figuras e se permitir deixar pedaços da obra sem inalização. A recomposição desse contexto que permite um tipo de inferência lógica, ainda que aproximativa - que indiquei aqui como abdução - é uma operação atribuída a Peirce, que José Ferrater Mora chama de "conjetura razoável": "os processos mentais, tanto de descoberta como de justificação ou explicação, são inferenciais. Isso quer dizer que pode haver razões para as inferências (que são, elas mesmas, 'razões'), até mesmo quando se formulam proposições ou se chega a conclusões aparentemente por mera 'conjetura' ou 'intuição'" (MORA, 2004 p.11-12).
Sérgio se lança numa operação semelhante, numa segunda ordem: procura "lacunas e contradições" nas narrativas clássicas produzidas pela historiografia da Arquitetura e, a partir das lentes da Economia Política, põe essa historiografia pelo avesso, reescrevendo-a a partir de baixo, do ponto de "vista do canteiro".

Em aulas realizadas na FAUUSP, em abril de 2004 e compiladas no volume " $A$ história da arquitetura vista do canteiro" (publicado em 2010), Sérgio consegue restabelecer a separação entre o projeto e a construção e o surgimento de uma espécie de forma ancestral da profissão já no processo de ressurgimento das cidades, entre os séculos IX e XI na Europa central - e não no Renascimento italiano, como faz a historiografia tradicional, estabelecendo a figura de Brunneleschi como patrono do ofício, muito em virtude das tietagens de Vasari.

As corporações medievais, que se empregavam na construção de catedrais, muralhas e castelos, atuavam contribuindo para carrear grandes quantidades de valor para os nascentes núcleos urbanos. Como diz Ferro, citando Le Goff, tais estruturas não foram objetivamente construídas tendo como argumento uma função puramente econômica, mas seguramente funcionaram como "motor da acumulação primitiva do capital". A riqueza trazida para as cidades circulava pagando materiais e operários, os quais "comiam, se vestiam, consumiam a produção local, formando assim um mercado urbano". Tal processo, promovendo economicamente as cidades, acabava solapando as motivações que levavam reis, nobres e bispos investirem naquelas estruturas: o comércio intra-urbano, o comércio exterior e os negócios urbanos passam a ser mais atraentes como atividade econômica, relegando as catedrais a segundo plano, condenando-as ao inacabamento que lhes é característico. Desse modo, as relações de trabalho começam a mudar, principalmente lá pelo final do séc. XII. Henri Pirenne, em sua "História Social e Econômica da Idade Média" é precioso na descrição dessas mudanças: com o predomínio dos negócios, as corporações passam a se sujeitar a estruturas comerciais e de investimento que lhes são exógenas, propiciando um novo formato de organização da manufatura através das corporações comerciais (PIRENNE, [1933] 1968, particularmente p.49, 184 e ss).

Sérgio Ferro cita o caso de Estrasburgo e da construção de sua catedral como exemplar: a cidade "tornou-se uma espécie de República e as negociações acaba- 
ram ficando mais complexas. Um conselho dirigia as obras [da catedral] e, para se obter um consenso, começou a ser necessário desenhar antes, fazer maquetes, prever. Surge assim a figura do intermediário, o que desenha o projeto-contrato" (FERRO, 2010 p.16). Sérgio o denomina como "protoarquiteto" e cita a figura de Mestre Erwin de Steinbach, responsável pela transmissão das ordens dos contratantes para os mestres das corporações, como uma espécie de ancestral da profissão - posteriormente transformado por Goethe e pelo movimento neogótico como o "grande herói da arquitetura gótica". De aí em diante essa separação entre o que desenha e aqueles que constroem só irá se aprofundar. Não coloca Brunelleschi (e suas astúcias no controle do trabalho no canteiro de Santa Maria del Fiori) como matriz inaugural da profissão e dessa separação, mas o coloca como referência importante nesse processo:

\begin{abstract}
"Assim, desde o tempo do nosso santo padroeiro (quase todas as histórias da arquitetura citam Brunelleschi como o primeiro protótipo de nossa profissão), o desenho passou a ser arma na luta de classes. Começou saindo de mansinho do canteiro, do qual era até então um momento. Logo, entusiasmado com a visão do todo que possibilitava e com os encantos de sua liberdade gráfica, se afastou das exigências técnicas do trabalho e dos materiais que, entretanto, comanda" (FERRO, 2010, p.19).
\end{abstract}

É desse modo que, escovando "a história a contrapelo" (BENJAMIN apud CONTIER, 2010 p.104), Sérgio consegue demonstrar, como neste exemplo, que o "arquiteto e desenho separado se constituíram ao mesmo tempo, e um é produto do outro: são interdependentes" (FERRO, 2010 p.14). E é essa interdependência que caracteriza e explicita a contradição entre desenho e canteiro - e não uma paralisante oposição, que interromperia a História como processo e Razão em movimento (isso é Hegel, voltaremos a essa questão mais adiante).

De certa forma, a aproximação metodológica promovida por Sérgio Ferro patrocina esse desvelamento de contradições. Ela não se dá mecanicamente, mas vem sempre problematizada e problematizando a si mesma. Isto significa que, a princípio, não segue um esquema pré-definido, mas se autoconstrói no processo de sua constituição. De certo modo, é como se, ao cutuca-la, a própria História desvelasse o que Ihe subjaz como estrutura. Algo talvez como o que Marx propõe no posfácio à segunda edição de "O Capital", ao estabelecer a diferença entre método de investigação e modo de exposição:
"Sem dúvida, deve-se distinguir o modo de exposição segundo sua forma, do modo de investigação. A investigação tem de se apropriar do material [Stoff] em seus detalhes, analisar suas diferentes formas de desenvolvimento e rastrear seu nexo interno. Somente depois de consumado esse trabalho é que se pode expor adequadamente o movimento real. Se isso é realizado com sucesso, e se a vida da matéria é agora refletida idealmente, o observador pode ter a impressão de se encontrar diante de uma construção a priori [ou seja, uma forma intemporal do pensamento]" (MARX, 2013 [posfácio da segunda edição de "O Capital", de 1873] p.90 - o adendo é meu).

Chego assim à minha segunda conjetura, derivada da primeira: para tomarmos a História como processo, em movimento, precisamos tomar "o material em seus detalhes" e "rastrear seu nexo interno", não em busca do que enxergamos, do que parece ser, mas em busca de suas mais íntimas contradições.

\section{III}

Sabemos, através de depoimentos do próprio Sérgio Ferro, o quanto a Lógica hegeliana e a concepção de dialética que lhe é peculiar sustentam suas empreitadas investigativas.

Hegel, segundo Marcuse ${ }^{9}$, estabeleceu como primeira tarefa de sua Lógica definir o pensamento especulativo como a "primeira exposição" de seu método dialético (MARCUSE, 2004 [1941] p.52): perante a "autoridade dos fatos", a Razão tem que ter a desconfiança como norma. Contraposto ao senso comum, ao mundo das percepções, das entidades finitas, "governado pelo princípio da identidade e da oposição", o pensamento precisa se colocar atento. Em última instância, essa contraposição é aquela que arranja, em campos opostos, Razão (Vernunft) e Entendimento (Verstand): uma operação que está na base de toda a arquitetura filosófica de Hegel e que põe em julgamento a trajetória inatista iniciada por Descartes algumas centenas de anos antes, bem como o empirismo inglês da turma de Locke e Hume e o "idealismo crítico" de Kant, como assim autodenominado nos seus Prolegômenos (KANT, [1783] 1988 p.64).

"Uso a obra "Razão e Revolução - Hegel e o advento da teoria social" (2004 [1941]), de Herbert Marcuse, como fonte explicativa do sistema filosófico hegeliano e estabelecimento das possíveis conexões com a obra de Sérgio (a lembrança e indicação foi de Silke Kapp, a quem agradeço) Faço essa aproximação a Hegel por segunda mão, portanto. Contudo, a partir de um autor plenamente avalizado para a tarefa, creio. Um estudo mais aprofundado das referências hegelianas de Sérgio Ferro deve ser empreendido em contexto mais amplo e mais intensamente debatido. 
"O pensamento especulativo compara a forma aparente ou dada das coisas às potencialidades delas, distinguindo assim, nas coisas, a essência do estado acidental de existência. Tal resultado não é atingido através de algum processo de intuição mística, mas por um método de conhecimento conceitual que examina o processo pelo qual cada forma veio a ser o que ela é. O pensamento especulativo não concebe 'o mundo material e intelectual' como uma totalidade de relações fixas e estáveis, mas 'como um vir-a-ser, e seu ser como um produto e um produzir'." (MARCUSE, 2004 [1941] p.51)

O pensamento especulativo procura vazar o véu do "interior das coisas" e não se deixar levar pela aparência fenomênica, pela aparência do que aparece. O exemplo que Sérgio nos oferece dessa operação trata justamente daquela oposição (assim determinada por uma abordagem, digamos, menos rigorosa) entre o desenho e o canteiro.

Em "O canteiro e o desenho", ao tratar do desenho em seu "consulado da representação", Sérgio é bastante telegráfico, seu texto chega a ser quase cifrado (FERRO, 2006 p.158). Articulando argumentos quanto ao papel do desenho no contexto da produção da Arquitetura, provoca e incomoda os arquitetos - particularmente a turma do desenho como senhor de si e dos desígnios da arquitetura: "É porque é desenho para a produção (de mais-valia) que se encolhe na grelha mongiana até virar sinônimo seu"... Mas, o que significa ser "igual a si mesmo"? Por que estabelecer o desenho como um idêntico a si mesmo? Sem dúvida, refere-se a "um universal concreto, uma verdade plena e 'superior", que 'absorveu' as identidades anteriores" (MORA, 2005 p.1431)

Ser "igual a si mesmo" é o Ser submetido ao princípio de identidade. Mas, para Hegel, a "identidade puramente formal do entendimento" difere da "identidade rica e concreta da razão". Como nos elucida Ferrater Mora, "a rigor, a própria forma do princípio de identidade indica, segundo Hegel, que há nele mais que uma identidade simples e abstrata; há o puro movimento da reflexão no qual o 'outro' surge como 'aparência"” (idem). O "outro" do desenho: o canteiro.

"Já dissemos que, no desenho, é como aparência de relação que as separações do fazer e do pensar, do dever e do poder, da força e dos meios de trabalho se manifestam. E que os laços que o desenho propõe são laços do separado mantido separado (Aparência: 'é o nome dado ao ser que imediatamente é em si mesmo um não-ser') (FERRO, 2006 p.159, grifo no original. A definição de 'aparência' é de Hegel, na "Fenomenologia do Espírito").
Para Ferro, o desenho é "materialização da separação, reificação da ruptura" (idem, p.159). Uma negação determinada, portanto.

Mas o que sinto é que o desentendimento (ou o "entendimento", no sentido de Hegel) de como se dá essa negação acaba prevalecendo, contribuindo para muito equívoco a respeito da construção teórica de Sérgio que já foi divulgado por aí: a formulação parece estar ali unicamente para negar a própria Arquitetura - agora identificada ao desenho. E daí a acusação de que Sérgio "não gosta de arquitetura" - o que não é verdade, bem me parece.

Como uma 'explicação da explicação', vai ser no inédito "A construção do desenho clássico" - um dos mais recentes trabalhos de Sérgio e que compõe a coleção de textos que vêm sendo preparados para publicação no âmbito do TF/TK (ou seja, ainda indisponível, infelizmente) - que o autor descreve como se dão as operações que dispõem o desenho não só contra o canteiro, como também em contradição a si mesmo. Transcrevo o trecho dessa análise do processo dialético de tratamento dos objetos, segundo formulação de Marcuse, como bula explicativa do que Sérgio vai demonstrar em seguida:

"As relações devem ser apreendidas de outra maneira [que não "simples 'correlações' pelas quais o senso comum vai ligando um objeto a outro"]. Elas devem ser vistas como sendo criadas pelo próprio movimento do objeto. O objeto deve ser compreendido como aquele que, ele mesmo, estabelece e 'ele mesmo propõe a relação necessária entre ele e o seu oposto'. Isto implicaria em que o objeto tivesse um poder definido sobre seu próprio desenvolvimento, de modo a poder permanecer o mesmo, e isto, apesar de cada estágio concreto da existência do objeto constituir uma 'negação' do objeto, um 'ser-outro'. Em outras palavras, o objeto deve ser compreendido como um 'sujeito' nas suas relações ao seu 'ser-outro'” (MARCUSE, 2004 [1941] p.70).

Qual o exemplo, então, Sérgio Ferro nos dá para elucidar essa relação que o desenho "propõe" ele mesmo entre "ele e o seu oposto"?

Historicamente, o desenho se separa do canteiro e se torna autossubsitente. Desse modo, ele nega o canteiro: passa a falar sozinho, tributário de uma plástica autônoma, de uma explicação orientada por diretrizes que não aquelas estabelecidas pela ordem material de sua produção. Surgem as teorias da arquitetura, as 
tendências analíticas e a taxonomia de complexas articulações com as construções culturais e suas diversas vertentes explicativas. No entanto, o desenho continua sendo projeto e, como tal, pressupõe o construído como futuro, como devir. Isto é, o desenho antecipa uma obra a se realizar e, portanto, um canteiro ideal. Assim, o desenho "passa a operar com um canteiro mental independente do canteiro real" (FERRO, 2020). É assim que ele entra em contradição consigo mesmo, com sua determinação material: ao mesmo tempo que nega o canteiro, ele precisa reafirmá-lo, idealmente, para sua autojustificação. Não se trata de opormos o canteiro ao desenho: essa oposição é momentânea e fruto do senso comum, como nos explica Marcuse:

"Onde quer que o senso comum e o entendimento percebam entidades separadas em oposição umas às outras, a razão descobre a 'identidade dos opostos'. Ela não produz tal identidade por um processo de conexão e combinação de opostos, e sim pela transformação dos opostos, de modo que estes deixam de existir como opostos, preservado embora o sentido deles em uma forma de ser que é mais alta e mais 'real'" (MARCUSE, 2004 [1941] p.52-53)

Terceira conjetura: assim como Hegel, o movimento do objeto, para Sérgio, não se dá em oposição ao sujeito. O objeto se coloca como sujeito e, desse modo, se transforma e entra em contradição. Não há oposição entre sujeito e objeto.

IV

Quarta conjetura: num passo adiante, assim como Marx, Sérgio parece concordar em inverter a dialética hegeliana. Em forma de coda, retomando a primeira conjetura, a História como processo só pode ser assimilada, não pela força mística de um Espírito aos modos de Hegel, mas pelo trânsito contraditório dos processos materialmente determinados, impulsionados por uma dialética que "dê conta de 'toda forma historicamente desenvolvida em seu estado fluido, em movimento" (HARVEY, 2013 p.21).

"Meu método dialético, em seus fundamentos, não é apenas diferente do método hegeliano, mas exatamente seu oposto. Para Hegel, o processo de pensamento, que ele, sob o nome de Ideia, chega mesmo a transformar num sujeito autônomo, é o demiurgo do processo efetivo, o qual constitui apenas a manifestação externa do primeiro. Para mim, o contrário, o ideal não é mais do que o material, transposto e traduzido na cabeça do homem. (...) A mistificação que a dialética sofre nas mãos de Hegel não impede em absoluto que ele tenha sido o primeiro a expor, de modo amplo e consciente, suas formas gerais de movimento. Nele, ela se encontra de cabeça para baixo. É preciso desvirá-la, a fim de descobrir o cerne racional dentro do invólucro místico" (MARX, 2013 [1873, cf. já indicado] p.90-91)

Parece-me necessário repensarmos a forma como investigamos nossos objetos, principalmente no contexto da investigação histórica. Aproximarmo-nos dos fatos buscando encontrar neles não oposições ou antagonismos evidentes - mas contradições. Substituir, como me parece a operação promovida por Sérgio Ferro, a "reflexão isolada (entendimento)" pelo "pensamento dialético (razão)", conforme a leitura de Hegel proposta por Marcuse (MARCUSE, 2004 [1941] p.52). Procurar entender como se dá a "transformação dos opostos", evitando encalharmos nos dualismos que, via de regra, se escondem entre as dobras de nossas abordagens historiográficas.

\section{V}

Daí, por fim, buscando trazer essas conjeturas para um campo mais prático, arriscando fazê-las ingressar na seara da historiografia em arquitetura.

Tomo como um primeiro exemplo a investigação sobre a construção com terra. Invariavelmente, boa parte da pesquisa sobre o uso da terra como material construtivo no Brasil se limita aos vínculos com os estudos do patrimônio e, nesse campo, essencialmente a edificações e contextos com conteúdos bastante paradigmáticos. Ora, as notícias e registros de como se dava a aplicação de mão-deobra na produção das edificações no período colonial é alguma coisa perto de quase nada. A não ser no que se refere às construções militares - quando alguns contingentes de escravizados eram recrutados para os trabalhos no canteiro, parcialmente também cumpridos pelos praças - além de uma ou outra edificação institucional mais proeminente - pouco se sabe sobre a construção doméstica, os verdadeiros canteiros de produção do urbano, de antes do advento da República. Pois vejam: quem eram os trabalhadores que construíram Ouro Preto, por exemplo? Quem eram os trabalhadores que erigiram a pacata vila da província de São Paulo, toda construída em terra, pedra e madeira até o começo do século XX? Certamente foram, em sua maciça maioria, africanos e seus descendentes, escravizados ou libertos que, dominando conhecimentos construtivos tradicionais e altamente especializados (como taipa de pilão, taipa de sopapo, cantaria, carpinta- 
ria etc.) que produziram boa parte, ao longo de todo o período desde sua chegada no Brasil, por volta de 1540, até os estertores do século XIX, de todo o patrimônio construído ao longo desses quase 400 anos. E pouquíssimo se sabe a respeito: como se organizavam esses canteiros? Pergunto aqui a João José Reis (REIS, 2019), historiador baiano que descreve com acuidade e de modo aprofundado toda a atividade laboral urbana conduzida por africanos na Salvador dos 1850, mais restrita à atividade de transporte de pessoas e gêneros naquela cidade, quem eram e como trabalhavam aqueles 'ganhadores' ou libertos que consumiam suas energias nos canteiros que produziam aquele pujante centro urbano na província da Bahia naquele período? Qual o volume de recursos envolvidos na produção daquela cidade? Quem eram seus principais investidores? Assim como nos nascentes núcleos urbanos na Europa da Idade Média, também essa atividade funcionava como "motor da acumulação primitiva do capital". Se as lógicas produtivas que subsidiaram o nascimento e o desenvolvimento dos nossos centros urbanos nos escapa, só nos resta a articulação de nomes, fatos, memória congelada e aparências de arquitetura e urbanismo ${ }^{10}$.

Outro exemplo.

Muito se fala, por exemplo, de Ramos de Azevedo e de sua importância para a História da Arquitetura, na virada do séc. XIX para o XX, e para o vertiginoso crescimento da construção civil, particularmente no estado de São Paulo. Atraindo e concentrando fabulosos volumes de capital que viabilizaram a transformação radical da cidade em pouco mais de 20 anos, a obra de Ramos de Azevedo e seu escritório já mobilizou um sem número de publicações sobre os empreendimentos sob sua responsabilidade. No entanto, falta-nos compreender, pelas lentes da Economia Política, como se estruturou o império empresarial de Ramos: desde

${ }^{10} \mathrm{Alguma}$ pesquisa vem sendo iniciada e orientada na direção que aqui indico. Trata-se do trabalho "Tebas: um negro arquiteto na São Paulo escravocrata", organizado pelo escritor e jornalista José Abílio Ferreira. A obra reúne ensaios e pesquisas sobre a atuação de Joaquim Pinto de Oliveira (1721-1811) profissianal prático do séc XVIII: negro "mestre pedreiro", Taquim Pinto de Oliveira (1721-1811), profissional prático do séc. XVIII: negro, "mestre pedreiro", Tebas foi o responsável, dentre outras obras até hoje existentes, pela cantaria que ornamenta a fachada da igreja contígua ao antigo Convento de São Francisco - hoje Faculdade de Direito da Universidade de São Paulo. Conforme José Abílio, apresentando Tebas, refere-se a ele como "senhor da arte de entalhar e aparelhar pedras, imprimindo no trabalho a marca pessoal e intransferível de sua identidade". O que o distingue, para além dos objetos arquitetônicos que produziu na província de São Paulo, seria o fato de que "conquistou autonomia sobre seu corpo e o seu destino, contrariando a lógica do regime escravista, baseada na fragmentação e na dominação absoluta (corpo e mente) dos escravizados" (FERREIRA, 2018 p.7). quando retornou de Gant, na Bélgica (sem sequer ter concluído sua formação como arquiteto) e assumiu as obras já quase finalizadas da Catedral de Campinas, interior do estado de São Paulo, um verdadeiro conglomerado empresarial cresceu e se consolidou sob a batuta de Ramos. Desde esse período - em que fica clara sua perspicácia empresarial - Ramos envolveu-se em negócios muito diversos (como produção de cal em Caieiras, implementação da indústria de vidro trazida da França, laminação de aço, produção de tijolos etc.), mas absolutamente concatenados com seus contratos e interesses de seu escritório ${ }^{11}$.

Um último exemplo.

O historiador britânico Michael Baxandall, em "Padrões de Intenção - a explicação histórica dos quadros" (numa referência aqui bastante rápida) propõe perseguir a "vontade ou intenção" por trás da fatura de um quadro. Diz o historiador que o que falamos dos quadros são "representações do que pensamos ter visto neles". No entanto, recusando a descrição que corresponde exclusivamente à "simples exploração com os olhos", Baxandall argumenta que, para que possamos apreender aquele objeto e todo seu processo de criação e produção, é preciso ir além da pura descrição do que vemos, lembrando que "usamos nossa mente, e a mente se vale de conceitos". Tal processo estaria ali, no quadro, como representação de "algo mais que um objeto material: implicitamente consideramos que ele contém não só a história do processo de trabalho do pintor, mas também a experiência real de sua recepção por parte dos espectadores" (BAXANDALL, 2006 p.38-39). Isso significa que, para além do objeto ali, presente, apresenta-se também como objeto portador de um material, de uma experiência de fruição contemplativa, de um processo de trabalho etc.

A proposta de Baxandall é muito pertinente, atinente a esta alternativa de aproxi-

${ }^{11}$ Cabe aqui mencionar pelo menos dois trabalhos que, de certo modo, levantam essa lebre: os mestrados de Thais Carneiro de Mendonça, "Técnica e construção em Ramos de Azevedo: a construção civil em Campinas", de 2010; e de Raquel Furtando Schenkman Contier, "Do vitral ao pano de vidro: o processo de modernização da arquitetura em São Paulo através da vidraçaria", de 2014 (MENDONÇA, 2010; SCHEKMAN CONTIER, 2014). Além desses, também em 2010, sob a coordenação de José Lira e minha, organizamos um Simpósio, através do Centro de Preservação da Cultura da Universidade de São Paulo - CPC-USP, denominado "Memória, trabalho ção da Cultura da Universidade de São Paulo - CPC-USP, denominado "Memoria, trabalho e arquitetura". O evento rendeu uma publicação homônima, reunindo 19 dos 20 trabalhos apresen tados naquela oportunidade, numa tentativa de abordar a história da produção da arquitetura sob
os vieses que venho aqui discutindo. Ver LOPES; LIRA, 2013. 
mação do objeto histórico, sem dúvida. A ideia de destacar o modo como um objeto de arte atravessa o tempo e chega até aquele que o observa, carregando um outro tempo e espaço para o tempo e espaço do observador através de seu material, seus signos, sinais e inferências do contexto em que foi produzido, assemeIha-se muito à estratégia que Sérgio Ferro emprega no tratamento que dá à sua análise da Capela dos Médici.

Mas ainda assim, há uma diferença crucial entre as abordagens dos dois.

O fato é que Baxandall faz uso não de um quadro, mas de uma ponte, para ensaiar 25 enunciados causais para propor uma estrutura de explicação histórica testemunhos de relações sociais, convenções, intenções etc. de uma época. Usa, para tanto, a Ponte sobre o Rio Forth, de Benjamin Baker, encomendada e construída entre 1873 e 1889 para integrar economicamente cidades como Aberdeen, Dundee, Edimburgo na Escócia e o norte da Inglaterra (BAXANDALL, 2006 p.49 e ss.)

A ponte é uma demonstração de virtuosismo estrutural impressionante: ao lançar balanços sucessivos por sobre o rio, fundeados e ancorados em enormes elementos tubulares e treliçados, a estrutura, toda fabricada em aço e operando conforme a lógica da compensação entre balanços, permite o vencimento de uma extensão de aproximadamente $1,5 \mathrm{~km}$, distribuídos em vãos sucessivos de em torno de $520 \mathrm{~m}$.

Baxandall relata brevemente a história da contratação e construção da ponte e, então, põe-se a indagar quanto às razões que teriam levado a construí-la, quanto às motivações do encargo geral encomendado a Baker e, neste exercício, enumera 25 evidências que auxiliariam na construção do que ele denomina "constructo descritivo".

No entanto, não formula uma questão que me parece crucial: de onde vinha o minério empregado na construção da ponte? Submetido às novas tecnologias de tratamento do ferro para transformá-lo em aço doce (sistema Siemens-Martin) lá na Inglaterra dos finais do 1800 , certamente esse minério saiu de algum profundo buraco no planeta, escavado por mão humanas.

Numa outra ponta, inadvertidamente, ficamos sabendo que a Mina de Morro VeIho, situada nos arredores de Nova Lima, no estado de Minas Gerais, próximo de onde hoje é Belo Horizonte, desabou no dia 10 de novembro de 1886. Com eloquentes $570 \mathrm{~m}$ de extensão, os escoramentos de seus túneis cederam sobre as cabeças e os corpos de um razoável contingente de africanos escravizados, negros libertos e alguns ingleses. Com 1.154 trabalhadores empregados na sua exploração, conforme contagem realizada em 1884, a proprietária da mina os distribuía em três turnos - o que dificultava a exata contabilização das vítimas do acidente. Essa proprietária chamava-se Saint John Del Rey Mining Company uma empresa britânica que, certamente, contribuiu para o abastecimento do minério necessário não só para a construção da ponte de Baker, como para o radical desenvolvimento industrial experimentado pela Inglaterra nesse período (TROCATE; COELHO, 2020).

Baxandall dá conta de que, na construção da ponte, foram consumidos " 3 milhões de libras e a vida de 57 operários" (BAXANDALL, 2006 p.56). Mas não dá conta do quanto de recursos, trabalho e gente foi consumido em toda a teia de produção envolvida nos rastros daquele empreendimento. Observar o objeto a partir dessa rede mais ampla, ampliaria também o regime de implicações históricas, transcendendo o espaço e tempo britânicos do final dos 1800. Transformaria sua explicação material e histórica numa questão universal.

\section{VI}

Os elementos e conjecturas aqui agenciados, como disse, pretendem apenas uma aproximação do problema de definição de um campo de estudos que se pretende denominar Production Studies. Certamente, deve haver outros aspectos, aqui não identificados, que contribuirão para a conformação desse campo. No entanto, acho correto afirmar que, para vislumbrar uma abordagem de investigação com as características aqui enunciadas, tanto histórica como sobre processos e práticas em arquitetura, devemos iniciar seguindo as ponderações de Adrián Gorelik:

"Poucas disciplinas têm maior impacto nas transformações da cultura, da vida social e econômica que a arquitetura. E, no entanto, as versões mais habituais de sua crítica e sua historiografia têm se empenhado em fazer dela um universo ensimesmado, esotérico, perdendo toda relação complexa com o mundo." (GORELIK, in LIRA, 2011 p.21) 
Para Gorelik, a "arquitetura precisa desse olhar estrábico para ser entendida cabalmente": um olho em si mesma e o outro nos "diversos contextos em que a arquitetura se intersecta e vai ganhando inteligibilidade" (idem).

\section{Referências}

ARANTES, Pedro Fiori. Arquitetura Nova: Sérgio Ferro, Flávio Império e Rodrigo Lefèvre, de Artigas aos mutirões. São Paulo: Editora 34, 2002.

BAXANDALL, Michael. Padrões de intenção: a explicação histórica dos quadros. São Paulo: Companhia das Letras, 2006 [edição original 1985].

CORIAT, Benjamin. "O processo de trabalho do tipo 'canteiro' e sua racionalização". Ata do Colóquio "Le travail en chantiers". São Paulo: mimeo (tradução Jorge Oseki, revisão João Sette Whitaker Ferreira), 1983.

CONTIER, Felipe. "História da arquitetura a contrapelo". In A história da arquitetura vista do canteiro - três aulas de Sérgio Ferro. São Paulo: GFAU, 2010.

FERREIRA, José Abílio (org.) Tebas: um negro arquiteto na São Paulo escravocrata. São Paulo: IDEA, 2018.

FERRO, Sérgio. $O$ canteiro e o desenho. São Paulo: Projeto Editores Associados, 1982 [edição original 1979].

. Arquitetura e trabalho livre. São Paulo: Cosac Naify, 2006.

A história da arquitetura vista do canteiro - três aulas de Sérgio Ferro. São Paulo: GFAU, 2010.

Michelangelo: arquiteto e escultor da Capela dos Médici. São Paulo: Editora WMF Martins Fontes, 2016.

. "Concrete as weapon". Harvard Design Magazine, v.46, p. 160-

08/161-33 (encarte) 2018

. A construção do desenho clássico. Grignan: mimeo (originais em preparação para publicação), 2020.

GORELIK, Adrián. "Apresentação". In LIRA, José. Warchavchik: Fraturas da vanguarda. São Paulo: Cosac Naify, 2011, p.21-23.

HARVEY, David. Para entender O capital. São Paulo: Boitempo, 2013

KANT, Immanuel. Prolegómenos a toda metafísica futura. Lisboa: Edições 70 , 1988 [edição original 1783].
KAPP, Silke; LLOYD THOMAS, Katie; LOPES, João Marcos de Almeida. "How to look at architecture from 'below'”. Harvard Design Magazine, v.46, p. 16001/161-06 (encarte), 2018.

KOURY, Ana Paula. Grupo Arquitetura Nova - Flávio Império, Rodrigo Lefèvre, Sérgio Ferro. São Paulo: Romano Guerra/EDUSP, 2003.

LLOYD THOMAS, Katie; AMHOF, Tilo; BEECH, Nick. Industries of Architecture. London: Routledge, 2015.

LOPES, João Marcos; LIRA, José. Memória, trabalho e arquitetura. São Paulo: Editora da Universidade de São Paulo - EDUSP, 2013.

MARCUSE, Herbert. Razão e revolução: Hegel e o advento da teoria social. São Paulo: Paz e Terra, 2004 [edição original 1941].

MARX, Karl. O capital: crítica da economia política: Livro I: o processo de produção do capital. São Paulo: Boitempo, 2013 [edição original 1890].

MENDONÇA, Thais Carneiro de. Técnica e construção em Ramos de Azevedo: a construção civil em Campinas (Mestrado). São Carlos: Escola de Engenharia de São Carlos - USP, 2010.

MORA, José Ferrater. Dicionário de Filosofia (4 volumes). São Paulo: Edições Loyola, 2004 [tradução referente à sexta edição, de 1976].

PIRENNE, Henri. História econômica e social da Idade Média. São Paulo: Editora Mestre Jou, 1968 [edição original 1933].

REIS, João José. Ganhadores: a greve negra de 1857 na Bahia. São Paulo: Companhia das Letras, 2019.

SCHENKMAN CONTIER, Raquel Furtado. Do vitral ao pano de vidro: o processo de modernização da arquitetura em São Paulo através da vidraçaria (Mestrado). São Paulo: Faculdade de Arquitetura e Urbanismo - USP, 2014.

SHIMBO, Lucia Zanin. Habitação social, habitação de mercado: a confluência entre Estado, empresas construtoras e capital financeiro (Doutorado). São Carlos: Escola de Engenharia de São Carlos - USP, 2010.

TROCATE, Charles; COELHO, Tádzio. Quando vier o silêncio: o problema mineral brasileiro. São Paulo: Fundação Rosa Luxemburgo, Expressão Popular, 2020. 